\title{
Promoting Global Carbon Equity and Low-Carbon Growth:
}

\author{
China's role in combating global climate change
}

Yongsheng Zhang

\section{Introduction}

Climate change has emerged as one of the greatest crises of the world today, and calls for global efforts to reduce greenhouse gas emissions and the dependence on traditional fossil fuels. The final solution to global climate change will require a greater reliance on a pattern of low-carbon growth based on renewable energy, which will represent the most profound transformation of the development model since the Industrial Revolution.

Two severe obstacles, however, stand in the way. First, effective international governance is absent, as the existing international order most reflects the interest of industrialised countries, yet handling the issue of climate change has a direct bearing on the future emission space (or development potential) of developing countries. If global climate negotiation is based on the arm-twisting of various countries, not on the principle of equity, this could give rise to unfair results (Garnaut 2008). Even though such unfair results might also contain climate change to some extent, this might well be achieved at the cost of underdevelopment in the world's developing countries. Second, the ideal of low-carbon growth has not become a common reality. Emissions reduction is deemed a burden and all countries have the incentive to be free riders in combating global climate change. In addition, the limitations of existing analyses fail to fully recognise the benefits of mitigation for economic growth. According to the existing analysis, global emission reduction conflicts with economic growth, such that fighting climate change becomes an issue of balancing its benefits and costs (for instance, Nordhaus 1993; Stern 2007). As a result, those involved in global negotiations on climate change focus more on how to share the burden, instead of on how to blaze out a low-carbon growth model via concerted and coordinated global efforts.

This focus on the burden of carbon reductions overlooks the fact that climate change negotiations could, through collaboration between industrialised and developing countries, be redirected from a zero-sum game to a win-win situation. This could be achieved through the simultaneous pursuit of global carbon equity and low-carbon growth. In both of these pursuits, China has an active role to play. In shaping the international climate change regime, China plays a key role in ensuring balance in the negotiations between industrialised and developing countries. On low-carbon growth, China is already making great efforts to transform its development pattern and promote low-carbon growth by robustly mitigating its emissions, adjusting its economic structure, and developing new energy sources. The objective of this chapter is to investigate China's role in combating global climate change, and the economic opportunities that fighting climate change represents. 


\section{Global carbon equity and low-carbon growth}

Due to the limited space for carbon emissions in the future, there are two possible scenarios for combating global climate change. The first is to control the emissions of global greenhouse gases (GHGs) while maintaining the existing pattern of world development. Under this scenario, industrialised countries would not need to drastically change their existing development and consumption patterns, but would need only to cut their current emissions by a certain margin. The majority of developing countries would, however, then likely be subject to long-term poverty due to the lack of enough emission space in the future. The second scenario is to establish a new low-carbon growth pattern in which industrialised countries dramatically alter their development and consumption pattern and developing countries shake off poverty by adopting a low-carbon growth pattern.

Obviously, the second scenario is optimal for the world as it can achieve two targets simultaneously - namely, the control of global GHG emissions and the boosting of global economic development for shared prosperity. Without great external pressure for further emission reduction, however, industrialised countries will not be motivated to shift to low-carbon growth. Should the most innovative industrialised countries lose the motive for transformation, the possibility of realising a global low-carbon growth pattern will become very slim. Hence, without carbon equity, the optimal second scenario cannot be achieved either. Carbon equity is therefore in the best interest not just of developing countries, but of the world as a whole.

According to the initiatives of the industrialised countries at the Copenhagen Climate Change Conference, global carbon emissions will be reduced by 50 per cent of those of 1990 by 2050, with an 80 per cent cut in GHGs by industrialised countries. Seemingly, industrialised countries have made a great commitment. Yet this is not true. Given the equation 'GHG emissions space for developing countries = global emission space in the future - emission space for industrialised countries', when the global emission space in the future and the emission space for the industrialised countries are given then GHG emissions space for developing countries is fixed. Setting the long-term goal of global temperature control at $2^{\circ} \mathrm{C}$ means that global emissions of carbon dioxide during 2010-50 need to be limited to $750 \mathrm{Gt}$ (WBGU 2009). In accordance with this initiative, developing countries will suffer from insufficient emission space, despite the reductions pledged by industrialised countries (Khor 2009).

\section{Global carbon equity and China's role}

The principle of common but differentiated responsibilities (CBDR) is fundamental to dealing with global climate change. Due to the absence of a clear definition for such responsibilities, however, industrialised countries often stress 'common responsibility' while developing countries place greater emphasis on 'differentiated responsibilities'. In particular, some industrialised countries regard it as unfair that China and the other largest developing countries do not undertake any compulsory emission reduction obligations as the major emitters in the world. So what is global carbon equity in the real sense? This can be addressed as long as 'differentiated responsibilities' are clearly defined. 


\section{The meaning of global carbon equity}

The project team of the Development Research Centre of the State Council (DRC 2009) proposed a solution of carbon budget accounts (CBA) for global GHG emissions reduction. Due to the mobility and inertia of GHGs, about 70 per cent of the GHGs currently in the atmosphere have been discharged by industrialised countries since the Industrial Revolution. Therefore, a global carbon budget should include both historical and future emissions. If a country's per capita emissions exceed the world average, it not only imposes a net negative externality on other countries, it also squeezes out their emission or development space, which should therefore be compensated. The initial emissions entitlements of each country should be allocated based on the per capita principle of accumulative emission entitlements. This is what we mean by global carbon equity.

In the first place, the aggregate global carbon budget including historical and future emissions should be set up in line with global long-term temperature control goals. Second, the budget should be allocated fairly among all countries in accordance with the per capita principle, and carbon budget accounts should be set up according to their initial emission entitlements and 'real' emissions. Third, an open and compatible mechanism for international cooperation and domestic emission reduction should be established on the basis of such accounts, by virtue of which all countries need to clear their account at the targeted time. In addition, relevant mechanisms for reporting, registration, verification and agreement compliance should be set up.

In accordance with this approach, the DRC project team gauges the differentiated responsibilities of each country through direct and indirect measurement (DRC 2010a). Direct measurement refers to the initial emission entitlements for each country based on a global carbon budget and per capita principle, while the real emissions are calculated directly in its historical accumulative real emissions. In light of the high lineal correlation between per capita gross domestic product (GDP) and per capita accumulative carbon dioxide emissions (Figure 9.1), an 'indirect' measurement is also adopted to gauge the differentiated responsibilities using current per capita GDP purchasing power parity (PPP) as a substitute indicator of accumulative real emissions (DRC 2010b). Both direct and indirect measurements have their own merits and demerits, but both show that industrialised countries register massive emission account deficits while developing countries enjoy a great account surplus. In this sense, the emission reduction commitment by industrialised countries lags far behind their responsibilities. The key results of the above two measurements are presented as follows. 
Figure 9.1 World average per capita GDP and per capita accumulative carbon dioxide emissions

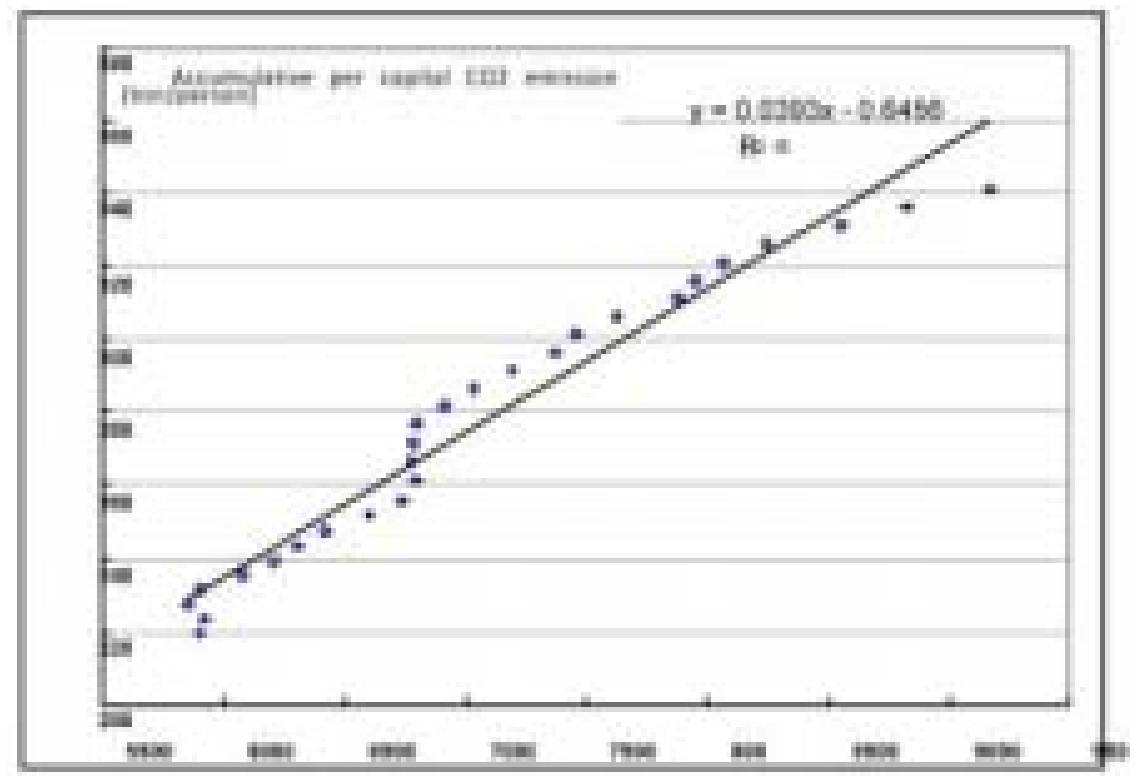

Source: DRC (2010b).

\section{Differentiated responsibilities of various countries by direct measurement}

According to Meinshausen et al. (2009), when the probability of the temperature exceeding $2^{\circ} \mathrm{C}$ is set at 25 per cent, the aggregate global carbon dioxide emission budget during 1850-2050 will stand at $2040 \mathrm{Gt}$ of carbon dioxide $\left(\mathrm{CO}_{2}\right)$. For a 50 per cent probability, the figure is $2477 \mathrm{Gt} \mathrm{CO}_{2}$ (Table 9.1). As can be seen from Table 9.2, under the second scenario, the deficit of Annex I countries (that is, industrialised countries)

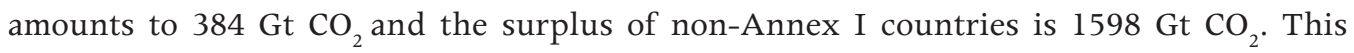
means that the industrialised countries would have no emission quota at all and would have to purchase emission rights from developing countries in order to maintain their current levels of production and consumption. Hence, the emission reduction commitment by the industrialised countries falls far behind their responsibilities.

Table 9.1 Aggregate global carbon dioxide emission budget during 1850-2050 with different probabilities of temperature rise exceeding $2^{\circ} \mathrm{C}$

\begin{tabular}{|l|c|c|}
\hline \multirow{2}{*}{} & \multicolumn{2}{|c|}{ Temperature exceeding probability } \\
\cline { 2 - 3 } & $25 \%$ & $50 \%$ \\
\hline Global emission budget during 1850-1999 & & 1040 \\
\hline Plus: global emission budget during 2000-49 & 1000 & 1437 \\
\hline Equals: aggregate global emission budget during 1850-2049 & 2040 & 2477 \\
\hline
\end{tabular}

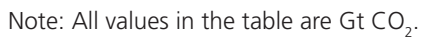

Sources: Meinshausen et al. (2009); and calculation of CAIT 7.0. 
Table 9.2 Balance of carbon budget account in 2006 with 50 per cent probability of temperature rise exceeding $2^{\circ} \mathrm{C}\left(\mathrm{Mt} \mathrm{CO}_{2}\right)$ : direct measure

\begin{tabular}{|l|c|c|c|}
\hline & $\begin{array}{c}\text { Initial emission } \\
\text { entitlements (1850-2050) }\end{array}$ & $\begin{array}{c}\text { Real emissions } \\
(1850-2006)\end{array}$ & $\begin{array}{c}\text { Balance of carbon } \\
\text { budget account (2006) }\end{array}$ \\
\hline World & 2477032 & 1258612 & 1218420 \\
\hline Annex I & 482593 & 867044 & -384451 \\
\hline Non-Annex I & 1967720 & 369177 & 1598543 \\
\hline
\end{tabular}

Notes: Figures for Annex I and non-Annex I do not add up to the World total due largely to calculation errors. All values in the table are $\mathrm{Gt} \mathrm{CO}_{2}$

Source: DRC (2010a).

\section{Differentiated responsibilities of various countries by indirect measurement}

For the indirect measurement, we apply per capita GDP to the Annex 1 countries and non-Annex 1 countries (Table 9.3). In general, the balance of carbon budget accounts in most countries through indirect measurement is close to the results of direct measurement with discrepancies for just a few countries.

Table 9.3 Balance of carbon budget account in 2006 with 50 per cent probability of temperature rise exceeding $2^{\circ} \mathrm{C}\left(\mathrm{Mt} \mathrm{CO}_{2}\right)$ : indirect measure

\begin{tabular}{|l|c|c|}
\hline & $\begin{array}{c}\text { Emission entitlements } \\
(1850-2050)\end{array}$ & $\begin{array}{c}\text { Balance of carbon budget account } \\
\text { (2006) }\end{array}$ \\
\hline World & 2477032 & 1218420 \\
\hline Annex I & 482593 & -314918 \\
\hline Non-Annex I & 1967720 & 1533338 \\
\hline
\end{tabular}

Source: DRC (2010a).

Both the direct and indirect measurements indicate that industrialised countries experience great emission deficits while developing countries generally have great emission surpluses. Such results genuinely speak for the differentiated responsibilities between industrialised and developing countries, which will not be changed by singletrack or dual-track global climate change negotiations. With clearly defined differentiated responsibilities, industrialised countries will receive emissions quotas from developing countries through various collaborations or an international emission trading scheme to maintain their development, which will provide crucial financing for developing countries to gain access to new green technologies and to adapt to climate change.

\section{On the starting point of historical responsibilities}

On this issue, a popular argument holds that the year 1990 should be the starting point for measuring the historical responsibilities of all countries as the assessment report of the Intergovernmental Panel on Climate Change (IPCC) was first published in 1990. Yet such an argument is unconvincing. 
First, the concept of 'common but differentiated responsibilities' was put forward as early as 1992, according to which differentiated responsibilities reflected the historical responsibilities of each country based on the impact of accumulative emissions on the environment by various countries from the Industrial Revolution through to 1992, not the carbon emissions of various countries from 1990 to the present. This point is reflected in the following two quotes.

- Rio Declaration (1992) (Principle 7): 'In view of the different contributions to global environmental degradation, States have common but differentiated responsibilities. The developed countries acknowledge the responsibility that they bear in the international pursuit of sustainable development in view of the pressures their societies place on the global environment and of the technologies and financial resources they command.'

- UN Framework Convention on Climate Change: 'Parties should act to protect the climate system "on the basis of equality and in accordance with their common but differentiated responsibilities and respective capabilities".'

Second, GHGs discharged by industrialised countries since the Industrial Revolution still harm developing countries today. Theoretically speaking, the historical responsibility of each country should therefore begin from the Industrial Revolution. In practice, given the lack of available historical data, balanced negotiations between industrialised and developing countries should establish a starting point that is acceptable to both parties.

\section{Typical arguments from industrialised countries on global carbon equity}

Since the differentiated responsibilities in the principle of CBDR have not been clearly defined, some industrialised countries fail to fully recognise their responsibilities in global emission reduction. Some people argue that industrialised countries have made a greater contribution to global emission reduction, while the developing countries - in particular, the major developing countries such as China - are the main obstacles in combating climate change (for example, see Miliband's comments on China in Coates and Macartney 2009). This argument seems to be supported by the fact that industrialised countries took the initiative to undertake compulsory emission reduction obligations in the Kyoto Protocol while developing countries did not. Also, with China emerging as one of the largest emitters in the world, with rapidly growing emissions, some people conclude that it is China rather than the historical emissions that underpins the current predicament for global emission reduction. The above calculations demonstrate that the emission reduction efforts by the industrialised countries fall far behind their responsibilities once differentiated responsibilities are clearly defined.

The following typical views of industrialised countries help to explain the disagreements between industrialised and developing countries on the issue of carbon equity.

'Our ancestors were not aware of the hazards of GHG emissions. Therefore, we are not responsible for the emission by our ancestors.' 
Such an argument is understandable but not convincing. In line with the legal principle of 'objective responsibility' (such as in the United States), polluters should not be exempted from responsibility by claiming an unawareness of the hazards to the environment.

'It is unfair to ask this generation to take responsibility for the emissions generated by their forefathers.'

First, the current high levels of economic and social development in industrialised countries could not have been achieved without the emissions generated by their forefathers. In this sense, people in the present industrialised world are the beneficiaries of the emissions generated by their forefathers. Given that these historical emissions still linger in the atmosphere, someone has to take responsibility for them and surely this should be the (richer) people in industrialised countries, rather than the (poorer) people in developing ones.

'Developing countries should not focus on the issue of history. Instead, they should try to avoid the mistakes we have made by actively reducing their own emissions.'

Historical responsibility and future emissions are two different issues. The former relates to the rights of each country and the latter is the issue of choosing the path to industrialisation. No matter which path developing countries take (that is, high or low carbon growth), it should not affect their emission entitlements subject to the global budget. Also, given historical emissions and the impact they have had on current global temperatures, there will not be sufficient room for the economic development of developing countries unless the industrialised countries accept their responsibilities.

Besides, it is a false proposition to urge the developing countries to avoid making the mistakes made by the industrialised countries. If there were a better road towards industrialisation, developing countries would follow it spontaneously without requiring persuasion by industrialised countries. The problem is, however, that until now, lowcarbon growth has not become a reality even in industrialised countries. Industrialised countries need to conduct more pilot projects based on new low-carbon patterns of growth for developing countries to follow. Before such patterns mature, they will be too risky for relatively poor countries to adopt.

'Being democratic means that our political processes will not allow us to take on so much historical responsibility or to have deep emissions cuts.'

This argument reflects reality, yet lacks legitimacy. A country's emission reduction responsibility has nothing to do with its democracy. Yet such reality speaks for the necessity of more effective global governance. How to establish more democratic and effective global governance remains a daunting challenge for solving global public issues such as climate change. 


\section{Low-carbon growth and China's contribution}

To reduce GHG emissions and combat global climate change, we ultimately need to shift to a low-carbon pattern of development. This is a major thread in China's Twelfth Five-Year Plan (2011-15). China is committed to reducing its carbon emission intensity (that is, emissions per unit of GDP) by 40-45 per cent by 2020 compared with 2005, and to raising the proportion of renewable energy in total primary energy consumption to 15 per cent. China has also formulated ambitious development plans for emerging industries of strategic importance, covering next-generation information technology, industries on energy saving and environmental protection, new energy, biology, high-end manufacturing equipment, new materials, and new-energy vehicles. As a result, China has recently become the world's largest investor in renewable energy, followed by the United States and Germany. These efforts are likely to have a significant positive impact on the world's future pattern of development.

\section{How emission mitigation promotes economic development}

According to mainstream neoclassical marginal analysis, there is a trade-off between emissions reduction and economic growth. In particular, given the current (or any previous) level of technology and economic structure, economic growth necessarily generates emissions. Holding both the level of technology and the economic structure fixed therefore implies that emission reduction, to a large extent, can come only at the expense of economic development. Therefore, the cost of emission reduction consists of two parts: 1) the direct cost of emission reduction; and 2) the output decrease due to emission reduction. The benefit of emission reduction is mainly the decrease in the damage caused by climate change. Since the cost of emission reduction is local while the benefit is global, each country has an incentive to be a free rider in emission reduction. In the framework of neoclassical marginal analysis, the optimal global emission reduction is to achieve an efficient trade-off between the (global) benefits of emission reduction and the (local) costs of reduction - that is, the standard marginal analysis.

If, however, emission reduction leads to a more efficient low-carbon division-of-labour model, the result will be very different. In this case, emission reduction might promote instead of hamper economic development. This line of thinking follows Smith (1776) and Young (1928) and is formalised by Yang (2001) with 'infra-marginal analysis', which argues that the technical level, industrial structure and hence economic growth will undergo noncontinuous change along with the evolution of the division of labour. This process is closely related to the Schumpeterian process of creative destruction.

Building on Smith and Young's ideas, Zhang and Shi (2010) develop an infra-marginal general equilibrium model that demonstrates how unilateral mitigation policy could actually stimulate the emergence and development of new industries associated with lowcarbon technologies, analogous with the unilateral tariff cutting in the United Kingdom that stimulated economic growth 200 years ago. In particular, the earlier adopter of stringent mitigation policy can enjoy first-mover advantages in specialisation and higher productivity, and, consequently, international competitiveness. Other countries will then adopt similar stringent mitigation policies so as to maintain and improve their competitiveness, leading 
to multilateral carbon reduction policy changes. Within this context, there is even the probability that developing countries could leapfrog to a more competitive low-carbon economic structure, since they have lower transition costs than industrialised countries, which have been already locked into high-carbon technologies.

Driven by national emission reduction policies and market competition, new final products will emerge one after another, coupled with the enlargement of industrial chains and the phasing out of old (especially emission-intensive) industries. Such changes can occur one by one or simultaneously. For example, motors can replace traditional petrol internal combustion engines and be built into electric vehicles, while at the same time the utilisation of wind power, nuclear power and/or carbon capture and storage technology can reduce the emissions per unit of electricity generated. In addition, the application of new technology can bring about changes to the whole industrial chain.

This means that the continuous development and expansion of low-carbon industries can become strong drivers of economic growth, resulting in fundamental changes in the development model, which would rely more heavily on the following

- low-carbon energy sectors: 1) new and renewable energy including wind, solar, hydropower, biomass, nuclear energy, ocean energy; 2) low-carbon fossil fuels such as shale-gas and liquefied natural gas (LNG); 3) and the 'cleaning' of high-carbon fossil fuels, such as 'dirty' coal

- upstream industries and services of low-carbon energy sectors, such as low-carbon energy generation equipment and services

- downstream industries and services of low-carbon energy sectors, including renewable energy-based industries (such as electric vehicles and their industrial chains)

- de-carbonisation of traditional high-carbon industries and the modernisation of agriculture, by using new technologies and business models (such as carbon asset management)

- low-carbon urban planning, infrastructure, and transportation systems

- low-carbon consumption patterns and lifestyles, which will further expand the markets for low-carbon products, as long as consumers are willing to pay a relatively higher price for low-carbon products.

\section{China's potential advantages in promoting low-carbon growth}

Industrialised countries have already fully developed their traditional fossil fuel capacities and related industries, so the development of low-carbon industries would be largely at the cost of the elimination of traditional capacity. For developing countries, however, low-carbon industries can develop without needing to eliminate traditional high-carbon industries. As China is still relatively less developed, it should be able to enjoy a relatively low cost of transformation, given the potential for developing its low-carbon industries by leapfrogging. 
China's massive domestic market creates an additional favourable condition for the development of low-carbon industries. Based on Adam Smith's (1776) fundamental argument that the extent of the market determines the extent of the division of labour, this gives China a unique advantage. In combination with the ongoing challenges facing Chinese leaders as they grapple with ways to cope with the country's almost insatiable demand for energy, it seems that both the potential and the incentives for low-carbon development are there.

Nonetheless, this does not necessarily make the task easy. The ability to take full advantage of potential latecomer advantages not only depends on strict emissions mitigation policy and the establishment of a market-based mechanism for emission reduction, but also depends on a solid market economic system. Ultimately, global competition for low-carbon growth is a competition among each country's institutions. These constitute the sufficient conditions for a country to get on a competitive low-carbon development path in the first place.

\section{The future of global climate change}

Zhang and Shi (2010) use their model to analyse the prospects for global climate change negotiations to solve the climate change problem. According to the analysis, the prospects for successful negotiations are rather thin. Despite these findings, we are in fact rather optimistic about finding solutions to the global climate change issue, and particularly about the unique role that China can play.

According to the goal of the Copenhagen Accord, global emissions during 2010-50 should be confined within $750 \mathrm{Gt} \mathrm{CO}_{2}$ (Meinshausen et al. 2009). Such emission space would be used up in 25 years given annual global emissions of more than $30 \mathrm{Gt} \mathrm{CO}_{2}$ in 2008 (WBGU 2009). Hence, under the current technology level and economic growth pattern, unless either the industrialised or the developing countries make a great concession for the sake of reaching a global agreement on emission reduction, the goal is simply not achievable. For this reason, no major breakthroughs are likely to be achieved in global climate change negotiations in the foreseeable future.

The ongoing climate change negotiations rely on a top-down approach, in which a global temperature control target is set in the first place and then the corresponding global emission space or emission reduction quota is allocated among countries. Due to the absence of effective global governance, this top-down approach has confronted enormous difficulties. Some people have lost confidence in any kind of top-down solution and instead place their hope on a 'bottom-up' solution - that is, one in which each country sets its own emission reduction goals and promotes low-carbon growth (see Howes 2010).

Despite the dim prospects for global climate change negotiations, the prospect for addressing the issue of global climate change is still relatively promising. According to Zhang and Shi (2010), countries that take the initiative to adopt strict emission reduction policies will take the lead in shifting to a more competitive low-carbon growth pattern. Other countries then will have to follow to avoid being left behind in international competition. Hence, the global climate change issue will eventually be solved by such a bottom-up approach. Nonetheless, it does not mean that the top-down approach should be abandoned 
in international negotiations. Without such pressure, many countries are unlikely to consciously adopt the strictest emission reduction policies at home since the pursuit of a low-carbon pattern of growth through emission reduction is regarded as risky before such a pattern is proved to be more competitive and feasible. Therefore, without emission reduction pressure exerted by top-down negotiation, industrialised countries are extremely unlikely to adopt rigid emission reduction measures. In this regard, the bottom-up solution to global climate change deeply relies on top-down negotiation, creating a serious dilemma for global climate change negotiations and comprehensive emission reduction.

\section{Conclusions}

Global carbon equity is a prerequisite for the solution to global climate change and lowcarbon growth is the fundamental way out. In both regards, China has an indispensable role to play. Without the efforts of China, together with other rising powers, to defend the right of developing countries in global climate change negotiations, global carbon equity is not likely to be realised and future development in the developing part of the world will be confined by limited emission space. Meanwhile, without global carbon equity, industrialised countries will lack sufficient incentives to explore low-carbon development patterns. As a result, the global shift to low-carbon growth in the future will remain a mirage.

To date, emission reduction has been deemed as more a burden than an opportunity, with global negotiations focusing more on how to share that burden than on seriously exploring avenues for shifting to low-carbon growth. Both industrialised and developing countries need to rethink their respective roles in addressing global climate change as well as their positions in global climate change negotiations. First, all parties need to consider more deeply the perspective and concerns of the other. But more importantly, the traditional mentality of treating emission reduction as burden sharing needs to be changed. The world is being presented with a great opportunity to explore low-carbon modes of growth, which, if successful, will provide a positive-sum game globally, with both economic and environmental benefits worldwide.

\section{Bibliography}

Coates, S. and Macartney, J. 2009, 'China to blame for failure of Copenhagen climate deal, says Ed Miliband', The Times, 21 December.

Garnaut, R. 2008, The Garnaut Climate Change Review, Cambridge University Press, UK.

Howes, S. 2010, The international effort on climate change: unravelling or shifting gear?, ANU East Asia Forum, 24 October 2010, Canberra.

Khor, M. 2009, 'Blame Denmark, not China, for Copenhagen failure', The Guardian, 28 December 2009. 
Meinshausen, M., Meinshausen, N., Hare, W., Raper, S. C., Frieler, K., Knutti, R., Frame, D. J. and Allen, M. R. 2009, 'Greenhouse-gas emission targets for limiting global warming to 2 degrees centigrade', Nature, vol. 435, p. 1158.

Nordhaus, W. D. 1993, 'Reflections on the economics of climate change', The Journal of Economic Perspectives, vol. 7, no. 4 (Autumn), pp. 11-25.

Project Team of the Development Research Centre of the State Council (DRC) 2009, 'Global greenhouse gas emissions reduction: an analytical framework and solution', in R. Garnaut, L. Song and W. T. Woo (eds) 2009, China's New Place in a World in Crisis: Economic, geopolitical and environmental dimensions, ANU E Press, Canberra, and Brookings Institution Press, Washington, DC.

Project Team of the Development Research Centre of the State Council (DRC) 2010a, Carbon budget account approach: measurement results and implications, [in Chinese], A report of Fighting Climate Change Project, Beijing.

Project Team of the Development Research Centre of the State Council (DRC) 2010b, Carbon budget account scheme: a new measurement, [in Chinese], A report of the project Fighting Climate Change Project, Beijing.

Rio Declaration on Environment and Development, <http:/www.un.org/documents/ga/ conf151/aconf15126-lannexl.htm>

Smith, A. 1776, An Inquiry into the Nature and Causes of the Wealth of Nations, [reprinted 1976], University of Chicago Press, Ill.

Stern, N. 2007, The Economics of Climate Change: The Stern review, Cambridge University Press, UK.

UN Framework Convention on Climate Change, http://unfccc.int/essential_background/ convention/background/items/2853.php

WBGU 2009, Solving the climate dilemma: carbon budget approach, A Report of the German Advisory Council for Global Change (WBGU), Berlin.

Yang, X. 2001, Economics: New classical versus neoclassical framework, Blackwell, Boston.

Young, A. 1928, 'Increasing returns and economic progress', The Economic Journal, vol. 38, pp. $527-42$.

Zhang, Y. and Shi, H.-L. 2010, How emission reduction promotes economic development, [in Chinese], A report of the Fighting Climate Change Project of the Development Research Centre of the State Council, Beijing. 